\title{
Comunicación y lucha armada. Tres propuestas de articulación a partir de la experiencia de Radio Noticias del Continente
}

\author{
Communication and armed struggle. Three analysis proposals based on the \\ experience of Radio Noticias del Continente
}

\author{
Carlos Rodríguez Esperón*
}

\begin{abstract}
Resumen: El presente trabajo adelanta una serie de ideas acerca de las posibles articulaciones que vinculan comunicación y lucha armada, en el marco del desarrollo de una investigación más amplia sobre la experiencia de Radio Noticias del Continente, emisora de onda corta impulsada por Montoneros en 1979 en Costa Rica.
\end{abstract}

Palabras clave: Comunicación alternativa; contrainformación; propaganda; lucha armada; Montoneros

\begin{abstract}
The present work advances a series of ideas about possible joints that link communication and armed conflict, into the framework of development of a broader investigation about the experience of Radio Noticias del Continente, shortwave transmitter driven by Montoneros in 1979 in Costa Rica
\end{abstract}

Keywords: Alter communication; counterinformation; propaganda; armed conflict; Montoneros

\section{Introducción}

El presen te trabajo se enmarca en una propuesta de investigación en curso, que busca dar cuenta de los modos de articulación que se presentan entre un medio masivo de comunicación perteneciente a una organización político militar y los objetivos políticos de la misma en función de su intervención en una coyuntura determinada. En tal sentido adelanta una serie de pistas para pensar la relación entre medios de comunicación y acción política revolucionaria, partiendo de una premisa general: no existe proceso político de transformación social que no implique, en una de sus dimensiones, una intervención activa en el campo comunicacional. Sintetizando podría decirse que no existe revolución sin prensa revolucionaria. Buscar un medio por el cual difundir la voz de aquellos marginados

\footnotetext{
* Argentino, Licenciado en Ciencias de la Comunicación, Universidad de Buenos Aires. caresperon@yahoo.com.ar
} 
del poder, aquellos que luchan por cambiar las condiciones que impone una determinada situación político social, es tan viejo como la prensa misma o más.

Las formas que adquiere esta relación específica entre comunicación y política han variado a lo largo de la historia, conformando diversas configuraciones. No es igual el uso de los medios que hizo el leninismo, que el que desarrollaron los zapatistas. Sin embargo, y a pesar de las diferencias, existe una línea en común que hilvana todas las experiencias que genéricamente se ubican en el campo de la comunicación alternativa y es que la acción comunicacional asume un carácter instrumental en función de los objetivos de intervención política que se persiguen.

En la búsqueda de comprender cómo se articulan los condicionamientos políticos que impone un proyecto revolucionario, con las características particulares que son propias del funcionamiento de un medio de comunicación, el caso de Radio Noticias del Continente aparece como una experiencia interesante ya que en la misma confluyeron los objetivos de una organización política armada como Montoneros, ilegalizada y perseguida en Argentina, con un conjunto de profesionales con diversas trayectorias particulares en el campo de la comunicación. Radio Noticias del Continente no fue un medio partidario surgido simplemente de la voluntad militante al calor de la lucha, sino que se trató de una radio realizada con criterios periodísticos de excelencia en la producción informativa, al servicio de una acción política transformadora.

\section{Radio Noticias del Continente}

Uno de los principales problemas que tiene el proceso de reconstrucción histórica de experiencias mediáticas no gráficas, es la falta del material emitido. En el caso de Radio Noticias del Continente, la totalidad de las emisiones se grababan y se sabe que el archivo íntegro de la radio pudo ponerse a salvo antes de la clausura de la emisor ${ }^{1}$. Los protagonistas de esta historia no han revelado públicamente el destino final de los mismos y sus razones deben ser respetadas, pero sí puede decirse que nadie sabe en qué estado se encuentra dicho material, que fue afectado por un huracán, según confirmaron tres fuentes diferentes y no vinculadas entre sí.

La poca cantidad de fuentes primarias hace que el testimonio de los protagonistas se vuelva el camino privilegiado para la reconstrucción de la experiencia, con los problemas lógicos que acarrea la decadencia de las memorias personales y las interpretaciones individuales de acciones políticas colectivas.

Señalado este problema, existe una coincidencia generalizada respecto a que la idea de montar una radio de onda corta fue producto de la necesidad de romper el cerco informativo impuesto por la dictadura argentina a partir del 24 de marzo de 1976. La salvaje represión encabezada por el Gral. Videla, hizo pagar con la vida todo intento de producir una información alternativa al régimen ${ }^{2}$, al tiempo que la Junta Militar ejercía un

\footnotetext{
${ }^{1}$ Raúl Cuestas, La dictadura militar argentina y el genocidio en Centroamérica, Córdoba, SIMA, 2005.

${ }^{2}$ Asociación de Periodistas de Buenos Aires, Con vida los queremos, Bs. As., UTPBA, 1986.
} 
férreo control sobre los contenidos cuya circulación se permitía. En este sentido hay que destacar que la tradición golpista nacional instalada desde 1930, con sus consecuentes restricciones a la circulación libre de la información y el ejercicio activo de la censura, motivó el desarrollo en paralelo de una creciente práctica de escucha de emisoras internacionales, en la búsqueda de una información diferente. El caso más conocido es el de Radio Colonia de Uruguay que, dada su cercanía geográfica con la ciudad de Buenos Aires, permite un fácil acceso con un simple receptor AM. Para los años '70 muchas familias adquirían el receptor de radio que comercializaba la empresa Noblex, con el nombre de "7 Mares", cuyo principal argumento de ventas era que permitía escuchar por onda corta, de una manera muy sencilla, emisoras de todo el planeta.

Un nuevo golpe de Estado, el más sangriento de la historia argentina, sumado a una tradición de escucha instalada en la sociedad a la hora de buscar información más fiable, hizo que emitir desde fuera del país se volviera una opción factible e interesante para Montoneros.

Entre las posibilidades existentes para la instalación de la emisora fuera de Argentina, el porqué de la elección de Costa Rica es algo sobre lo que no existe consenso entre los protagonistas de la experiencia. Hasta ahora la versión que mayor grado de confirmación tiene, vincula la elección con el ofrecimiento de explotación de una licencia preexistente que, transmitido a la conducción de la organización Montoneros en septiembre de 1976, es aceptado por ésta y da comienzo al desarrollo de toda la estructura técnica y periodística, que demanda la puesta al aire de una radio de onda corta de alcance mundial. Desde el diseño y construcción de la antena o la fabricación de un transmisor especial, ya que no había otro con esa potencia, hasta la elección de quienes integrarían el plantel periodístico o productor de contenidos en general, pasando por la organización administrativa y de seguridad, todo se hizo a lo largo de tres años, a partir de un núcleo fundador de militantes montoneros que no llegaba a diez personas ${ }^{3}$.

Desde su origen la radio vinculó su trabajo cotidiano al devenir político de los movimientos y organizaciones revolucionarias, principalmente latinoamericanas, que tenían por objetivo la transformación radical de las sociedades en que intervenían. Este aspecto ya se puede observar desde la primera transmisión oficial. La radio comenzará a realizar emisiones de prueba a finales de 1978 y comenzará a transmitir oficialmente en julio de 1979, unos días antes del triunfo de la revolución Sandinista. Existe cierta confusión respecto a que la radio comenzó sus emisiones como Radio Sandino, pero esto no fue así. En una reunión realizada al norte de Costa Rica, los líderes sandinistas Daniel y Humberto Ortega le habrían planteado a Fernando Vaca Narvaja, quien se encontraba a cargo de la Secretaría Internacional de Montoneros, que evaluara con la conducción de la organización la posibilidad de poner la radio al servicio de la ofensiva final sandinista. Radio Sandino, que según distintas fuentes era una emisora de baja potencia, en virtud de las condiciones del enfrentamiento militar, no alcanzaba a cubrir de manera permanente la totalidad del

\footnotetext{
${ }^{3}$ Junto con Miguel Regueyra Edelman, docente de la Escuela de Ciencias de la Comunicación Colectiva de la Universidad de Costa Rica, estamos trabajando en la reconstrucción de la historia de Radio Noticias del Continente, con vistas a la publicación de un libro sobre la misma. La información sobre la emisora que aquí se publica, es producto de dicha investigación.
} 
territorio nicaragüense. La potencia de RNC, que le permitía una transmisión de escala planetaria, garantizaba que todas las columnas que confluirían sobre Managua conocieran de forma simultánea los detalles de la ofensiva final. De esta forma la radio, puesta a transmitir al servicio de las necesidades político-militares del sandinismo, lo hizo conservando su identidad.

A partir de ese momento y hasta febrero de 1981, la radio pondrá sus emisiones a disposición de todos los movimientos revolucionarios del mundo, sin nunca olvidar que su objetivo central estaba enfocado en Argentina. Esto generó la extraña paradoja de que la radio fue muy poco escuchada en Argentina fuera de los sectores de la población más comprometidos políticamente, mientras su influencia en Centroamérica fue muchísimo más alta, al punto que la densidad de artículos publicados en la prensa gráfica centroamericana, es muy superior al impacto en la prensa argentina.

A pesar de esta realidad comunicacional, tanto el Gral. Videla como su continuador, el Gral. Viola, no ahorraron esfuerzos para sacar del aire a la emisora. Son conocidos los atentados sobre la planta transmisora y los estudios, llevados adelante por comandos argentinos con el apoyo de los contras nicaragüenses, en el marco de las operaciones militares que desarrolló la dictadura argentina en Centroamérica. A tal punto la eliminación de la radio era un objetivo central, que se convirtió en el primer operativo conjunto llevado adelante por ex guardias somocistas, entrenados por militares argentinos, con información y asistencia logística de la CIA, inaugurando un modelo de cooperación en la represión, que asolará Centroamérica en esos años ${ }^{4}$.

Desde el ametrallamiento del frente del estudio ubicado en San José de Costa Rica, hasta el intento fallido de arrojar una bomba sobre la planta transmisora, usando un avión procedente de Honduras, ingentes fueron los esfuerzos por destruirla, mientras de manera paralela crecían las presiones políticas ejercidas sobre el gobierno de Rodrigo Carazo Odio, impulsadas por la derecha costarricense y de manera particular por el Movimiento Costa Rica Libre ${ }^{5}$, que no perdió oportunidad de aparecer en la prensa de ese país, fustigando el quehacer cotidiano de la radio y su apoyo al "terrorismo".

Finalmente, la emisora será clausurada en febrero de 1981, usando como excusa que a partir de una denuncia se allanaron las instalaciones, encontrándose una gran cantidad de armas. Lo cierto es que, al momento del allanamiento, sólo se encontraron algunas pistolas propiedad del personal de seguridad. El proceso legal seguido contra la directora de la radio, Ana Lorena Cartín Leiva, demostraría que esto era realmente así. Para ese momento la totalidad de las instalaciones de Radio Noticias del Continente, incluido su potente transmisor, ya habían sido puestos a salvo en Nicaragua evitando el decomiso que incluía la orden de clausura. La comandancia montonera evaluó la posibilidad de instalar los equipos en Managua y seguir desde allí con las labores. Pero el contexto internacional había cambiado desde la asunción de Ronald Reagan en enero de 1981 y la dirigencia sandinista no estaba convencida de prestar su territorio para que la emisora continuara transmitiendo.

\footnotetext{
${ }^{4}$ Ariel Armony, La Argentina, los Estados Unidos y la cruzada anticomunista en América Central, 19771984, Bs. As., Universidad Nacional de Quilmes, 1999, 57-58.

${ }^{5}$ Organización paramilitar creada por la CIA.
} 
Finalmente, la idea de continuar irá perdiendo su atractivo para Montoneros, en definitiva, la radio no había tenido los resultados esperados en su llegada a Argentina. Hacia fines de ese mismo año la organización decidirá enfocarse en otro proyecto comunicacional, poniendo fin definitivamente a Radio Noticias y con ella a una de las experiencias de comunicación alternativa más interesantes que haya conocido nuestro continente americano.

\section{Un pequeño recorrido por el campo de la comunicación alternativa}

El principal problema que debe asumir todo investigador que ubique su trabajo en el campo de la comunicación alternativa, es que no existe una definición consensuada acerca de que prácticas pueden o no integrar el mismo. Desde una perspectiva epistemológica, siguiendo la propuesta de Gilberto Giménez ${ }^{6}$, el término "comunicación alternativa" se configura como una noción más que como un concepto, atendiendo a su ambigüedad y a las dificultades de formalización que históricamente se han dado desde sus primeras utilizaciones. Julio Cortázar, desde otro campo, decía que "el diccionario tiene una definición para cada cosa; cuando son cosas muy concretas, la definición es tal vez aceptable. Pero muchas veces a lo que tomamos por definición yo lo llamaría una aproximación. La inteligencia se maneja con aproximaciones y establece relaciones y todo funciona muy bien, pero frente a ciertas cosas la definición se vuelve verdaderamente difícil"”.

Tomando esta idea de aproximación que propone Cortázar, una perspectiva para comenzar a delimitar las problemáticas de la comunicación alternativa es la periodización que realiza el investigador chileno Fernando Reyes Matta, para quien este campo se alimenta de cuatro vertientes históricas, que irán surgiendo a partir de la finalización de la Segunda Guerra Mundial:

Las luchas frente al colonialismo. En la década del ' 60 y principalmente en el norte de África y en Asia, los movimientos independentistas debían enfrentar no sólo el proceso de organización política de los nuevos países, además debían afirmar un perfil cultural que les diera identidad, de allí la necesidad de contar con nuevos mecanismos de expresión y definir nuevas prioridades informativas distintas a las impuestas por las potencias coloniales.

Las reacciones nacionales e internacionales contra el neocolonialismo. Durante la década del '70 surge con fuerza un movimiento de reacción contra las condiciones de dependencia en que se encuentra el Tercer Mundo en general. En un contexto caracterizado por la expansión transnacional y la denuncia sobre la dominación económica, son fenómenos determinantes los planteos sobre la dominación informativa y cultural.

\footnotetext{
${ }^{6}$ Gilberto, Giménez, "La teoría y el análisis de la cultura. Problemas teóricos y metodológicos", Jorge González y Jesús Galindo Cáceres (Eds.), Metodología y cultura, México, Pensar la cultura, 1994.

${ }^{7}$ Julio Cortázar, Clases de literatura. Berkeley, 1980, Buenos Aires, Alfaguara, 2013, 26.
} 
Movimiento por la calidad de la vida y dimensión humana del desarrollo. Se intenta dar cuenta aquí de las acciones encaradas por muy heterogéneos movimientos en el seno de las sociedades postindustriales de desarrollo capitalista y que presentan diversas formas de expresión, por ejemplo, los movimientos por la liberación de la mujer, por el rechazo al armamentismo y el peligro nuclear, por los abusos del control estatal, por la ecología, etc.

Las reacciones frente a los autoritarismos políticos y económicos. La comunicación alternativa se liga a las formas de expresión y resistencia que generan los movimientos populares y las organizaciones de base en situaciones de dominación política (principalmente dictaduras militares) y de concentración del poder (económico, cultural, etc.) en grupos privilegiados al interior de cada sociedad ${ }^{8}$.

Cada una de las disputas, enfrentamientos y conflictos en que cristalizaron estas vertientes en cada país en particular, tuvo su correlativa acción comunicacional. Una intervención específica en el universo de lo simbólico, siempre articulada con objetivos que se desprenden de la lucha política en todas sus formas.

En el marco de esta articulación entre acción política / acción comunicacional, es posible distinguir una reflexión propiamente latinoamericana sobre el campo de intervención que define dicha articulación y que ha recibido una gran cantidad de denominaciones, siendo las más utilizadas las de comunicación popular y comunicación alternativa ${ }^{9}$. Sin importar a priori cuál de estas denominaciones se utilice, ambas coinciden en plantear la existencia de una articulación particular inescindible entre acción comunicacional y compromiso político con la transformación social. Al respecto decía Jesús Martín Barbero en 1983

En América Latina, la comunicación popular es comunicación planteada en términos de las mayorías; de las mayorías dominadas, y por tanto ligada no solamente a un fenómeno de contracultura, y mucho menos a un fenómeno de marginalidad, sino ligada a los movimientos sociales, a los procesos de dominación y de réplica a la dominación, y por tanto atravesada por un proyecto, o al menos, por un movimiento de lucha política ${ }^{10}$.

A la manera de Eric Hobsbawm con el siglo XX, en lo que respecta al campo de la comunicación latinoamericana, podríamos hablar de la década extra larga de los '70, la que

\footnotetext{
${ }^{8}$ Fernando Reyes Matta, Comunicación alternativa y desarrollo solidario ante el mundo transnacional. ILET, México, 1981. Citado en Mar de Fontcuberta y José Luis Gómez Mompart, Alternativas en comunicación, Barcelona, Ed. Mitre, 1983, 23-24.

${ }^{9}$ Cfr. Raúl Fuentes Navarro, Un campo cargado de futuro: El estudio de la comunicación en América latina, México, ITESO, 1991. El autor señala 33 términos diferentes que se han utilizado en diversos trabajos latinoamericanos para tratar de dar cuenta de las experiencias comunicacionales surgidas por fuera del circuito hegemónico de los medios.

${ }^{10}$ Jesús Martín Barbero, “Comunicación popular y los modelos transnacionales”, Revista Chasqui 8, 1983, 5.
} 
se enmarcaría entre la aparición en 1972 de Para leer al Pato Donald, de Ariel Dorfman y Armand Mattelart y la publicación en 1987 de De los medios a las mediaciones. Comunicación, cultura y hegemonía de Jesús Martín Barbero, que efectivamente viene a condensar los ejes principales de un nuevo paradigma asentado sobre la noción de hegemonía, a partir de relecturas de Gramsci más acordes con los tiempos de recuperación democrática que ya se venían dando en varios de los países de nuestro continente.

En esta década larga, el compromiso político del investigador, del periodista, del comunicador, compromiso con una transformación social que erradique las condiciones de inequidad en que viven las grandes mayorías, es sin dudas un valor central que define la comunicación popular o alternativa y que algunos autores denominan "Modelo latinoamericano".

Inserción y organicidad fueron los rasgos decisivos de la politicidad de la comunicación popular como lugar de expresión del conflicto y de búsquedas de articulaciones capaces de construir espacios de poder, lugar de expresión de la opresión y la subalternidad y de visibilización y discusión de ideas, proposiciones, modos organizativos y prácticas tendientes a revertirlas (...) El "modelo latinoamericano" se caracterizaba por su variedad y pluralidad justamente en función de ese enraizamiento específico. ${ }^{11}$

Inserción y organicidad se vuelven valores indispensables a la hora de la acción política, en un marco donde, de manera creciente, el campo de la comunicación comienza a ganar terreno como espacio de lucha y conflicto, lugar privilegiado para la disputa por el sentido de la realidad. Esta vinculación orgánica entre intervención política y comunicacional queda claramente expresada en palabras de Margarita Graziano, quien en 1980 proponía que la expresión comunicación alternativa se reserve "para aquellas relaciones dialógicas de transmisión de imágenes y signos que estén insertas en una praxis transformadora de la estructura social en tanto totalidad"12.

Los foros internacionales no son ajenos a estas discusiones, que en ese momento le están dando un espesor político a las prácticas de los medios de comunicación como nunca antes en la historia. En 1973, a partir de la cuarta Conferencia de Países No Alineados realizada en Argel, comenzará a desarrollarse un movimiento crítico a nivel mundial que colocará en el centro del debate político los desequilibrios globales en la producción, circulación y recepción de la información. Este movimiento adquirirá un fuerte carácter institucional cuando la UNESCO en 1976, en Nairobi, comisione a su Director General, Amadou-Mahtar M'Bow, para que realice un informe acerca de "todos los problemas de comunicación de la sociedad contemporánea en el marco del progreso tecnológico y de los desarrollos recientes de las relaciones internacionales"13.

\footnotetext{
${ }^{11}$ María Cristina Mata, “Comunicación popular. Continuidades, transformaciones y desafíos”, Revista Oficios terrestres 26, 2011, 8 .

${ }^{12}$ Margarita Graziano, "Para una definición alternativa de la comunicación”, ININCO 1, 1980, 71.

${ }^{13}$ Sean MacBride (ed.), Un sólo mundo, voces múltiples: comunicación e información en nuestro tiempo, México, Fondo de cultura económica, 1980, 14.
} 
El senegalés conformará la Comisión Internacional para el Estudio de los Problemas de la Comunicación, cuyo informe final, presentado en 1980 en Belgrado y conocido comúnmente como Informe MacBride en honor a quien se ocupó de presidir el trabajo de dicha comisión, se convirtió en un diagnóstico inapelable acerca de las desigualdades existentes a nivel internacional en esta materia, expresando a su vez una serie de propuestas que plantean las condiciones de posibilidad para establecer un Nuevo Orden Mundial de la Información y la Comunicación (NOMIC).

Los problemas de la comunicación alcanzan por primera vez estatuto global. Las industrias culturales no escapan a la tendencia creciente a la concentración de la producción en pocas manos que caracteriza al desarrollo capitalista. Desde fines de los ' 60 y desde EEUU, Herbert Schiller ya había comenzado a denunciar el poder que progresivamente irían adquiriendo las industrias culturales norteamericanas y su funcionalidad en la construcción de un consenso social que contribuye a sostener un orden mundial de desigualdad. El informe Mac Bride será la coronación de un movimiento crítico que surge desde la economía política de la comunicación, en el cual la democratización y la participación aparecen como dos vectores indispensables sobre los cuales trabajar en la construcción del NOMIC.

En este punto se puede percibir la existencia de dos líneas. Por un lado, la propuesta de un NOMIC identificado en las proposiciones del Informe Mac Bride, poniendo el acento en la necesidad de modificar las estructuras materiales que organizan la producción, circulación y recepción de la información a nivel mundial, como parte de un movimiento democratizador de la sociedad. Por otro un modelo latinoamericano que, desde el paradigma de la comunicación popular y alternativa, demanda un compromiso político efectivo del comunicador con la transformación política de su sociedad.

La experiencia de Radio Noticias del Continente aparece como una síntesis posible entre ambas líneas señaladas. La emisora se definió a sí misma como un claro exponente de ese NOMIC planteado por la UNESCO, a la vez que no ocultó su compromiso con todos los movimientos revolucionarios de la época (no sólo latinoamericanos), además de estar vinculada orgánicamente con un grupo político armado, Montoneros, que la pensó desde su origen como una herramienta de lucha contra la dictadura argentina. En un documento publicado a nombre de la radio y fechado en Managua en abril de 1981, puede leerse lo siguiente:

El manejo fragmentario de la información, la distorsión de los hechos, el cierre de los canales a ciertas fuentes que no condicen con el "orden establecido", no son más que algunos de los instrumentos utilizados por un tipo de comunicación: la desinformación. Herramienta estratégica de una maniobra más vasta utilizada por el imperialismo en América Latina: la dominación económica, política, militar y cultural.

Desde el día en que Radio Noticias del Continente empezó a nacer, aún como proyecto en un sinnúmero de papeles, fue concebida como una 
emisora claramente alineada tras el concepto del Nuevo Orden Informativo Internacional, auspiciado por la $\mathrm{UNESCO}^{14}$.

En el marco de este contexto internacional, la experiencia de la radio impulsada por Montoneros en Costa Rica se presenta como un buen ejemplo para estudiar cómo se desarrolla la relación entre práctica política y práctica comunicacional, relación presente en todos los proyectos de comunicación alternativa que, vinculados a movimientos de transformación social, aún hoy se pueden observar en distintos lugares del mundo.

\section{Articulaciones posibles entre comunicación y política}

La gran diferencia entre un medio de comunicación alternativo y el resto de los medios, estriba en la condición instrumental que el mismo asume en virtud de una estrategia de política de transformación social. Mientras los medios hegemónicos se escudan tras un devaluado concepto de libertad de expresión, que es funcional al ocultamiento de los variados intereses políticos y económicos de la empresa mediática, los medios alternativos colocan el condicionamiento político como factor fundamental para comprender su acción comunicacional.

Esta perspectiva establece una relación directa entre las necesidades y condicionamientos que un contexto determinado impone a la intervención política, y el uso que se haga de un medio de comunicación en virtud de dicha intervención. De esta manera la autonomía del medio se ve restringida y las prácticas comunicacionales quedan sujetas al desarrollo de los objetivos políticos.

Este tipo de relación, que establece una disposición jerárquica entre fuerzas sociales que interactúan en una determinada coyuntura o contexto, y en la cual una de ellas es dominante respecto a las demás, en el campo de los estudios culturales se denomina articulación ${ }^{15}$. En el caso de la comunicación alternativa, los objetivos políticos expresan los límites entre los que se desarrollará la acción mediática, como es posible observar en la experiencia de Radio Noticias del Continente.

Entrevistados dos miembros de la conducción de Montoneros, ambos coincidieron en señalar que el proyecto de la emisora aparece como producto de una evaluación política propia, a partir de dos necesidades puntuales que impone el nuevo contexto generado por el golpe de Estado de marzo de 1976 en Argentina:

1) Llegar con información propia o con sus interpretaciones de la situación política, social y económica argentina, a un público que observaba inerte el crecimiento explícito de la censura y la represión. ¿Cómo denunciar los secuestros, torturas, desapariciones y asesinatos que en toda su desmesura no tenían lugar en los medios hegemónicos? ¿Cómo dar a conocer el proyecto desindustrializador de la dictadura y su reemplazo por una

\footnotetext{
${ }^{14}$ Radio Noticias del Continente, "La voz de los sin voz”, Managua, mimeo, 1981, 2.

15 Al respecto véase (et. al), Conceptos clave en comunicación y estudios culturales, Buenos Aires, Amorrortu, 1997.
} 
organización financiera de la economía nacional, centrada en la especulación y el endeudamiento, marginando a los sectores más vinculados a la producción?

2) La necesidad de establecer un canal de comunicación con los militantes que proseguían la lucha en el país. Esta necesidad se puede entender de dos maneras: una como mecanismo de cohesión interna de Montoneros, indispensable en el marco de las acciones represivas llevadas adelante por la dictadura argentina, otra como factor de organización de las acciones político-militares en el territorio. Un determinado mensaje emitido por la radio podía conllevar un tipo de escucha particular dirigida a un grupo de militantes, en virtud del cual se desarrollarán, o no, determinadas acciones.

En este punto aparece claro el rol del factor comunicacional en la lucha armada, así como la imposibilidad de reducir el mismo sólo a acciones de prensa.

A partir de lo expresado y aceptando lo provisorio de toda definición que forma parte de un trabajo que se encuentra en curso, se puede comenzar a proponer la existencia de tres tipos de articulación entre comunicación y lucha armada, a saber: I. Contrainformación; II. Propaganda; y III. Organización de la acción territorial.

I.- La contrainformación se puede pensar desde dos perspectivas. Por un lado, define la posibilidad de poner en circulación interpretaciones diferentes (propias) sobre la información que difunde la prensa hegemónica ${ }^{16}$. Este es uno de los abordajes más extendidos que, si bien no está mal, conlleva un inconveniente que se puede sintetizar en una frase: Por más que tomemos un diario como Clarín y lo leamos de la manera que queramos, siempre estaremos leyendo Clarín. En términos específicamente comunicacionales, esta idea de contrainformación deja a la misma atrapada dentro de los límites de la agenda informativa que construyen los medios hegemónicos, siguen siendo ellos los que deciden los temas importantes a ser tratados y puestos en circulación.

Afirmando que la disputa en el campo simbólico es parte sustancial de la lucha política, habría que ampliar la definición de contrainformación, incluyendo también el dar cuenta de los temas y problemas que la prensa tradicional niega, lo que implica que un medio alternativo intervenga activamente en el establecimiento de otra agenda temática, definida en virtud de los objetivos políticos de la organización que lo impulsa.

Este tipo de articulación propuesta aparece nombrado por los miembros de la conducción montonera como una de las razones que motivan el impulso de instalar una emisora de radio, como ya se señaló anteriormente.

II.- Bajo el término "propaganda" se agrupan una importante cantidad de acciones propias del campo de la comunicación, que van desde las acciones más llanas de difusión hasta la construcción identitaria de un grupo político, desde la búsqueda de adhesión a la lucha que sume apoyos y gane militantes comprometidos con la misma, hasta el fortalecimiento de la cohesión interna y el sentido de pertenencia colectiva. Estas intervenciones comunicacionales pueden estar dirigidas a distintos destinatarios, internos o externos a la organización, según el objetivo que se persiga.

\footnotetext{
${ }^{16}$ Cfr. Armando Cassigoli, "Sobre la contrainformación y los así llamados medios alternativos", Máximo
} Simpson Grinberg (comp.), Comunicación alternativa y cambio social, México, Premia Editora, 1986, 67-68. 
La propaganda es sin duda el tipo de articulación más estudiado a lo largo de la historia, al punto de opacar la posibilidad de plantear otro tipo de relaciones. Desde Edward Bernays en adelante, el empleo del término vinculado a las ideas de manipulación, persuasión e influencia sobre la recepción, ha hegemonizado una gran parte de los estudios en el campo de la comunicación y no existe ninguna organización, sea revolucionaria o no, que haya escapado a sus prácticas.

III.- La organización de la acción en el territorio refiere a un tipo particular de uso del medio de comunicación en la lucha armada y responde a las necesidades políticomilitares de la organización. Este es uno de los puntos más controvertidos en esta propuesta de articulaciones entre comunicación y acción política, ya que algunos de los protagonistas de Radio Noticias del Continente niegan rotundamente que la emisora haya sido utilizada para enviar mensajes particulares (cifrados), con el fin de coordinar alguna clase de acción en el país. Otros no tienen problema de asegurarlo, como Jorge Falcone cuando dice:

La segunda fase de la contraofensiva, por ende, supuso instalar a lo largo y ancho del país unidades de producción autónomas de no más de tres o cuatro compañeros, capacitados para hacer tareas políticas de base y de agitación, como las populares interferencias televisivas (RLTV), producidas con pequeñas subestaciones de emisión de breves proclamas grabadas, a difundir en un radio de hasta 60 manzanas a la redonda. Cada grupo recibiría consignas de un mando central, cifradas en la emisión de onda corta de la radio que la fuerza poseía en Costa Rica (Radio Noticias del Continente) para apoyar a los procesos de emancipación de América Central ${ }^{17}$.

Otro ejemplo es el reconocido comienzo de las emisiones de Radio Noticias del Continente, que colocó a la emisora en el rol de instrumento de coordinación de la ofensiva final sandinista sobre Managua, señalando los avances de cada columna sobre la capital nicaragüense.

Dejando de lado por un momento la radio, es posible reconocer este tercer tipo de articulación en otra experiencia vinculada a Montoneros. El excelente trabajo que sobre ANCLA realizó Natalia Vinelli ${ }^{18}$, muestra que la misma dependía orgánicamente del Departamento de Informaciones e Inteligencia de Montoneros, no de la Secretaría de Prensa. Quienes venimos del campo de la comunicación, en general estamos acostumbrados a estudiar el accionar de ANCLA en tanto agencia de noticias clandestina, poniendo en circulación información ocultada por la dictadura de Videla, o sea un emprendimiento propiamente comunicacional y mediático más allá de las condiciones de su implementación, y no como instrumento de acción en el campo militar. Recordemos lo que decía Walsh respecto a que la elección del nombre de la agencia tenía el objetivo de crear

\footnotetext{
17 Jorge Falcone, Montoneros, hijos del 55, recuperado de www.elortiba.org/pdf/Jorge_Falcone_Montoneros.pdf

${ }^{18}$ Natalia Vinelli, ANCLA. Una experiencia de comunicación clandestina orientada por Rodolfo Walsh, Buenos Aires, La Rosa Blindada, 2002.
} 
confusión entre las filas de las FFAA. Que la agencia de noticias estuviera vinculada al área de inteligencia, habla precisamente del rol que Montoneros otorgó a la producción y circulación de la información, en tanto insumo importante en su lucha armada contra el régimen dictatorial de Videla.

A manera de síntesis provisoria sobre cómo operaron estas tres articulaciones propuestas, se puede señalar un artículo publicado por el diario La Prensa en octubre de 1980, que explícitamente y desde una posición de denuncia orientada por su apoyo a la dictadura, dice sobre la radio:

\begin{abstract}
Una radio montonera
Radio TIRLR, de Costa Rica, es una emisora que demuestra una preocupación un tanto llamativa por lo que pasa en la lejana Argentina. En su audición "La voz del campo" se dedica, entre otros tópicos, no sólo a criticar la política económica de nuestro actual gobierno, sino que desarrolla lo que podría calificarse de todo un "plan de lucha" para el agro argentino: coordinación de las actividades gremiales y cooperativas; movilización masiva de los productores pequeños y medianos; extensión del radio de acción de un así llamado "frente o movimiento de salvación nacional" a otros sectores sociales: obreros de la industria, empresarios industriales, comerciantes, las diversas comunidades religiosas ${ }^{19}$.
\end{abstract}

La nota publicada por La Prensa es mucho más larga, pero alcanza este párrafo para señalar el rol de la radio en función de una situación específica. En este texto se habla de críticas a la política económica (contrainformación), desarrollo de un plan de lucha, coordinando y movilizando la acción de los pequeños y medianos productores (organización de la acción territorial) y extender la composición de un frente de salvación nacional a otros sectores de la sociedad (propaganda). Más allá de que estamos en presencia de un artículo publicado por uno de los periódicos que más apoyó la salvaje dictadura argentina, queda clara la coincidencia con los objetivos que llevaron a Montoneros a colocar una radio fuera del país, mostrando a su vez la viabilidad del análisis en términos articulatorios.

\title{
A manera de conclusiones transitorias
}

Como lo expresan los periodistas vascos Carlos Egia y Javier Bayón:

La información vertida por los medios es prácticamente la única oportunidad que el ciudadano tiene de conocer aquello que sucede en las esferas que le afectan y a las que, sin embargo, no tiene acceso directo por medio de sus propias posibilidades (...) A partir de esa información, el

\footnotetext{
${ }^{19}$ Manfred Schönfeld, “¿Qué tiene que ver una radioemisora instalada en Costa Rica con los problemas del agro argentino?", Buenos Aires, Diario La Prensa, 17 de octubre de 1980, 9.
} 
individuo podrá empezar a tener elementos para juzgar y evaluar las situaciones que le afectan y ante las que tendrá que responder. La ecuación es bastante simple: si la información es controlada, seleccionada e incluso distorsionada, el individuo partirá de una base parcial, sesgada y probablemente falsa para formar su juicio ${ }^{20}$.

Es muy difícil transmitir con mayor claridad la importancia de intervenir activamente en el campo de lo simbólico, en tanto dimensión fundamental en cualquier proceso de transformación social. Mucho más si de conflictos armados estamos hablando, cuando las posiciones en disputa se radicalizan y la información puesta en circulación, opera como un arma más en el combate.

Con esta perspectiva en mente se puede plantear que Radio Noticias del Continente fue una de las experiencias más importante de comunicación alternativa de alcance mundial, interviniendo protagónicamente en un campo dominado por los grandes jugadores en la producción de contenidos, que a su vez hegemonizan los medios que aseguran la circulación de los mismos. Uno de los resultados más conocidos del trabajo realizado por la Comisión MacBride, expuso cómo para 1980 cerca del ochenta por ciento de la información que circulaba en el mundo, era producida por sólo cinco agencias de noticias, marginando en la construcción del relato social a una gran cantidad de sectores de la población mundial. En este contexto Radio Noticias del Continente mostró que es posible realizar un periodismo comprometido políticamente y que a la vez responda a los parámetros de un nuevo orden mundial de la información y la comunicación más justo.

Cómo ya se expresó a lo largo del artículo, la investigación sobre esta experiencia se encuentra en curso. El trabajo que viene realizando Miguel Regueyra Edelman en Costa Rica, ha permitido recuperar en estos últimos meses algunas emisiones importantes que se encontraban en manos de quienes fueron protagonistas de esta historia, como el descargo público de Ana Lorena Cartín Leiva ante las presiones finales que producirán el cierre de la emisora, donde la directora expresa con lujo de detalles los ejes que guiaron su accionar, así como las presiones políticas sufridas, detallando cada uno de los atentados de que fue objeto. También se recuperó una emisión especial de 90 minutos a un año de la Revolución Sandinista y el crudo de la locución de la audiencia del Tribunal Permanente de los Pueblos, al momento de tratar el caso argentino. Con paciencia, en la web es posible encontrar el informe radial de Javier Zaffora ${ }^{21}$, donde es posible escuchar algunos fragmentos de emisiones y separadores. La desclasificación de archivos realizada por la Cancillería Argentina, permitió conocer los cables que la misma intercambiaba con la embajada en Costa Rica en relación a la situación de la emisora. El material que se encuentra disperso es abundante y todavía necesita de un tiempo de elaboración antes de poder arribar a conclusiones más certeras sobre el rol y el funcionamiento de la radio. Sin embargo, lo relevado hasta el momento, incluyendo los testimonios de quienes trabajaron diariamente

\footnotetext{
${ }^{20}$ Javier Bayón y Carlos Egia, Contrainformación. Alternativas de comunicación escrita en Euskal Herria, Bilbao, Likiniano Elkartea, 1997, 16

${ }^{21}$ Javier Zaffora, "El otro lado del cerco: la historia de TIRL Radio Noticias del Continente”, Bienal de Radio México, 2008.
} 
en la emisora, permite dar un primer sustento a la propuesta de articulaciones entre comunicación y política que aquí se avanzó.

La actualidad nos muestra, como nunca antes en la historia, la constitución del campo comunicacional en objetivo estratégico de toda disputa política, más allá de las formas que la misma pueda adquirir en los distintos contextos en que se desarrolle. Queda abierta la posibilidad de que esta proposición articulatoria expresada, se extienda al análisis de otras experiencias pasadas o presentes, en la búsqueda de alcanzar una mayor comprensión sobre hechos y situaciones que aún hoy, parecen estar tapadas por el barro de la historia.

\section{Bibliografía}

Armony, Ariel, La Argentina, los Estados Unidos y la cruzada anticomunista en América Central, 1977-1984, Bs. As., Universidad Nacional de Quilmes, 1999.

Asociación de Periodistas de Buenos Aires, Con vida los queremos, Bs. As., UTPBA, 1986.

Bayón, Javier; Egia, Carlos, Contrainformación. Alternativas de comunicación escrita en Euskal

Herria, Bilbao, Likiniano Elkartea, 1997.

Cassigoli, Armando, "Sobre la contrainformación y los así llamados medios alternativos" en Máximo Simpson Grinberg (Comp.), Comunicación alternativa y cambio social, México, Premia Editora, 1986.

Cortázar, Julio, Clases de literatura. Berkeley, 1980, Buenos Aires, Alfaguara, 2013.

Cuestas, Raúl, La dictadura militar argentina y el genocidio en Centroamérica, Córdoba, SIMA, 2005.

Falcone, Jorge, Montoneros, hijos del 55:

www.elortiba.org/pdf/Jorge_Falcone_Montoneros.pdf

Fuentes Navarro, Raúl, Un campo cargado de futuro: El estudio de la comunicación en América latina, México, ITESO, 1991.

Giménez, Gilberto, "La teoría y el análisis de la cultura. Problemas teóricos y metodológicos", Jorge González \& Jesús Galindo Cáceres (Eds.), Metodología y cultura, México, Pensar la cultura, 1994.

Graziano, Margarita, "Para una definición alternativa de la comunicación", Revista ININCO 1, 1980.

MacBride, Sean (Ed.), Un sólo mundo, voces múltiples: comunicación e información en nuestro tiempo, México, Fondo de cultura económica, 1980.

Martín Barbero, Jesús, “Comunicación popular y los modelos transnacionales", Revista Chasqui 8, 1983.

Mata, María Cristina, "Comunicación popular. Continuidades, transformaciones y desafíos", Revista Oficios terrestres 26, La Plata, 2011.

O'Sullivan, Tim (et. al), Conceptos clave en comunicación y estudios culturales, Buenos Aires, Amorrortu, 1997.

Radio Noticias del Continente, "La voz de los sin voz", Managua, mimeo, 1981.

Reyes Matta, Fernando, Comunicación alternativa y desarrollo solidario ante el mundo transnacional. México, ILET, 1981. Citado en Mar de Fontcuberta y José Luis Gómez Mompart, Alternativas en comunicación, Barcelona, Mitre, 1983. 
Schönfeld, Manfred, “¿Qué tiene que ver una radioemisora instalada en Costa Rica con los problemas del agro argentino?", Diario La Prensa, Buenos Aires, 17 de octubre de 1980.

Vinelli, Natalia, ANCLA. Una experiencia de comunicación clandestina orientada por Rodolfo Walsh, Buenos Aires, La Rosa Blindada, 2002.

Zaffora, Javier, "El otro lado del cerco: la historia de TIRL Radio Noticias del Continente", Bienal de Radio, México, 2008. 